\title{
Biological Approach in Teeth Vital Clearance: Case Report
}

\section{Manuel Delgado Morón*}

Universidad Justo Sierra, Professor of Dentistry at the University UCAD, Private practice in Esthetic Dentistry and Prosthetics, Mexico *Corresponding Author: Manuel Delgado Morón, Universidad Justo Sierra, Professor of Dentistry at the University UCAD, Private practice in Esthetic Dentistry and Prosthetics, Mexico.

Received: August 22, 2019; Published: September 26, 2019

DOI: $10.31080 / A S D S .2019 .03 .0651$

\section{Abstract}

The Lightening Treatments Improve the aesthetic quality of Patients present dyschromias WHO, Achieving pleasant smiles, with the development of techniques and lightening materials, Minimally invasive procedures are Carried out. In the market there are different possibilities to lighten teeth: such as over-the-counter teeth, as well as lightening gels for the exclusive use of the oral health professional, ITS mechanism of action OCCURS eleven the Lightening Gel Makes Contact with the tooth Allows it to be carry out the dental clearance, Obtaining predictable results and biological substrates respect to dental sensitivity if present.

Keywords: Dental Rinse; Hydrogen Peroxide; Aesthetics

\section{Introduction}

Dental aesthetics has played a significant role for humans because it is believed that the clear teeth are representative of health, beauty and youth. Currently, the dental bleaching is recognized as being efficient therapeutic procedure teeth having intrinsic and extrinsic discolorations both $[1,2]$. is considered a biologically safe treatment when a protocol is followed, besides that there is scientific evidence that supports them [3]. Developing dental clearance has a number of advantages compared to less conservative aesthetic alternatives mutilating increasing, the rise in the population by this cosmetic procedure.

The public asks clearer pleasant smiles, teeth, recovering with this cosmetic procedure greater self-esteem translating this in a communication skill interactive $[4,5]$. Clarifying Before starting therapy is necessary to carry out the diagnosis by evaluating the patient's oral health (free caries, defective restorations, leaks, cracks, periodontal disease and gingival recession etc) if there are some doubts you will need to clear it before starting clearance. Higienico is essential to know the dietary habits of the patient, lightening agents available and their mechanism of action to suit the needs of each patient.

The technique of dental clearance is not current, the first dental clearance was documented by Trauman in the year 1848 [6] using chloride to apply to a devitalized tooth vital teeth clearance was documented in the year of 1868. [7] for the year 1910 clearance recommended in vital teeth with hydrogen peroxide associated with a heat source. Van Haygood and Herald Heymann [8] spread the technique of "Night dental clearance" published in March 1989 by the International Quintessence magazine loaded with guards using carbamide peroxide brightening revolutionizing this process.
There are three techniques for vital teeth clearance; [1]. Lightening with OTC (over-the-counter), [9,10]. products without professional supervision which have increased in popularity in recent years, available in strips clearance, prefabricated guards, liquids and brushes as well as toothpastes. It is indicated to use twice daily for two weeks. However, it is the obligation of professional oral health counseling patients about potential harmful effects and warn them. [2]. The technique at home; It has the following advantages administration by the patient, less time in the dental chair, high security, low cost. carbamide peroxide is used in different concentrations $(10 \%, 15 \%$ and $22 \%)$ must be monitored by the treating dentist and the patient must cooperate in the treatment to achieve predictable aesthetic results. However, this technique has drawbacks, since compliance by the patient is required is why the technique has a high dropout rate, the color change depends solely patient.

Eleven 3. The clearance technique in office; It is performed by the professional who takes full control of the art from start to finish as high concentrations of hydrogen peroxide $\left(\mathrm{H}_{2} \mathrm{O}_{2}\right)$ ranging from 30 to $38 \%[12,13]$. Mechanism of action are used; peroxides are highly unstable and when in contact with the tooth surface, dissociate in water and free radicals latter by their low molecular weight penetrate the enamel and dentin substrates to carry the lightening effect due to the ability to oxidize chromophores causing the pigmentación [14].

The technique requires the practitioner to remain alert throughout the clarifier and process that may have adjacent gingival effects such as irritation, ulceration, tooth sensitivity. Should be carefully isolate the patient's soft tissues and carry out the use of 
gloves, goggles, the team must wear sleeve for long robes management brightener gel.

\section{Clinical Case Report}

A female patient 26 , dental care request presented as main complaint the color had his teeth, the patient requests a clarifying treatment that does not require long treatment.

Before starting treatment clinical medical history it was made not reporting significant systemic involvement and pregnancy medical supervision which was denied. a detailed study of their eating habits (food and beverage) consumption frequency, if you have tooth sensitivity was performed. In the anamnesis he denied a dental clearance have been done before, so I was asked about same expectations about the clarifier treatment. A clinical inspection conditions contraindicating not lightener procedure are observed, it was proposed to the patient lightener office treatment with hydrogen peroxide 35\% was explained the advantages and disadvantages of the art.

\section{Materials and Technical}

To use this technique rinsing gel (Clariant Angelus ${ }^{\circledR}$ Office 35\%, Angelus ${ }^{\circledR}$ Brazil). He prophylaxis with pumice was performed on the two dental arches. Subsequently the soft tissues of the patient and placing the gingival barrier polimeri zándola the time indicated by the manufacturer protected. Mixed (30 times) the brightener syringes aforementioned gel until a uniform color. was applied on the facial surface of the maxillary anterior teeth having a thickness of $2 \mathrm{~mm}$, after 15 minutes the gel was removed, the technique was repeated in the lower teeth the same time as in the previous upper 15 minutes. After completing the two sessions without clearance sensitivity report, the results are obvious, thus meeting the aesthetic expectations of the patient.

\section{Conclusions}

The clearance technique in office using brightener based gel hydrogen peroxide (35\% Clariant Angelus ${ }^{\circledR}$ Office, Angelus ${ }^{\circledR}$ ) satisfactory results were obtained carrying out systematic biological respect besides not cause tooth sensitivity.

\section{Bibliography}

1. C Kose., et al. "Comparison of the effects of in-office bleaching times on tooth whitening and sensitivity: a single blind, randomized clinical trial". Operative Dentistry 41 (2016): 138145.

2. Bortolatto JF., et al. "Low concentration H2O2 / TiO_N in office bleaching: a randomized clinical trial". Journal of Dental Research 93.7 (2014): 66S-71S.

3. Matis BA., et al. "Eckert GJ Extended at-home bleaching tetracycline-stained teeth of different Concentrations of carbamide With peroxide". Quintessence International 33.9 (2002): 645655.
4. Joiner A. "Tooth color: a review of the literature". Journal of Dentistry 32.1 (2004): 3-12.

5. ST Henson., et al. "Best AM Influence of dental esthetics social on perceptions of adolescents Judged by peers". American Journal of Orthodontics and Dentofacial Orthopedics 140.3 (2011): 389-395.

6. Dwinelle. "Ninth annual meeting of American Society of Dental Surgeons of". American Journal of Dentistry 1 (1850): 57-61.

7. C Atkinson. "Fancies and some facts". Dent Cosmos 34 (1892): 968-972.

8. Haywood VB., et al. "Nightguard vital bleaching". Quintessence International 20.3 (1989): 173-176.

9. G Kugel. "Over the counter TOOH withening systems". Compendium of Continuing Education in Dentistry 24.4 (2003): 376-382.

10. Kim E. "The increment of the Popularity of the dental bleaching”. Dimensions of Dental Jouranl Hygienic 3.11 (2005): 30-31.

11. Leonard RH Jr., et al. "Nightguard vital bleaching of tetracycline- stained teeth: 90 months post treatment". Journal of Esthetic and Restorative Dentistry 15.3 (2003): 142-152.

12. Da Mata AD and Marques DN. "A novel technique for in-office bleaching with a $6 \%$ hydrogen peroxide paint-on varnish". The European Journal of Esthetic Dentistry 1.1 (2006): 70-77.

13. Reis A., et al. "Efficacy of AD and effect on tooth sensitivity of in-office bleaching gel Concentrations: a randomized clinical trial". Operative Dentistry 38.4 (2013): 386-393.

14. Kashima- Tanaka M., et al. "Generation of free radicals and / or active oxygen by ligth or Lasser irradiation of hydrogen peroxide or soduium hypoclorite". Journal of Endodontics 29.2 (2003): 141-143.

\section{Volume 3 Issue 10 October 2019} (C) All rights are reserved by Manuel Delgado Morón. 